\title{
Pavio Erótico: uma experiência de Suzano na prevenção das DST/HIV/Aids e fomento da arte erótica
}

\section{Pavio Erótico: an experience in the prevention of STD/HIV/ Aids and incentive to erotic art in the City of Suzano}

\author{
Ademiro Alves de Sousa (Sacolinha) \\ Graduado em Letras. Prefeitura de Suzano (Secretaria de Cultura). \\ Endereço: Rua Guarani, 413, Jd. Revista, CEP 08694-030, Suzano, \\ SP, Brasil. \\ E-mail: sacolagraduadoळgmail.com \\ Maria Aparecida Lucareski \\ Especialista em Saúde Pública, educação e saúde. Prefeitura de \\ Suzano (Secretaria de Saúde). \\ Endereço: Rua Baruel, 430, Vila Costa, CEP 08675-902, Suzano, \\ SP, Brasil. \\ E-mail: malucareskiळhotmail.com \\ Regina Vianna Brizolara \\ Especialista em Saúde Coletiva. Prefeitura de Suzano (Secretaria \\ de Saúde). \\ Endereço: Rua Baruel, 430, Vila Costa, CEP 08675-902, Suzano, \\ SP, Brasil. \\ E-mail: reginabrizolaraळgmail.com

\section{Célia Cristina Pereira Bortoletto} \\ Especialista em Saúde Pública. Prefeitura de Suzano (Secretaria \\ de Saúde) \\ Endereço: Rua Baruel, 430, Vila Costa, CEP 08675-902, Suzano, \\ SP, Brasil. \\ E-mail: saudeœsuzano.sp.gov.br

\section{Walmir Pinto} \\ Graduado em Jornalismo e Arte Cênicas. Prefeitura de Suzano \\ (Secretaria de Cultura). \\ Endereço: Rua Benjamin Constant, 682, Centro, CEP $08674^{-0}$ olo, \\ Suzano, SP, Brasil. \\ E-mail: walmiratorळig.com.br
}

\section{Resumo}

Em 2006, as Secretarias de Cultura e de Saúde de Suzano estabeleceram uma parceria para implantar o projeto Pavio Erótico, que consiste em um sarau temático,com a exibição de filmes, declamação de poesias, mesas de diálogo, interpretação de contos, apresentação teatral, dança, música, além da disponibilização de preservativos e materiais informativos, que fomentam as discussões do universo da sexualidade humana à luz das práticas sexuais seguras. 0 evento tem edições trimestrais, com divulgação por meio de folders, cartazes, agenda cultural, convites e no site da Prefeitura do município. Seu público-alvo são escritores, poetas, artistas, professores e a comunidade em geral. Dentre os resultados alcançados com o projeto estão o incentivo à leitura e à arte erótica; divulgação dos serviços de saúde possibilitando a ampliação e o acesso a exames, orientações, distribuição de preservativos, além da realização do I Concurso de Literatura Erótica de Suzano. Essa proposta inovadora expressa a concepção de saúde não focada na doença e promove o desenvolvimento da cultura na cidade de Suzano.

Palavras-chave: Ação intersetorial; Doenças Sexualmente Transmissíveis; Prevenção e controle; Literatura. 


\section{Abstract}

In 2006, the Health and Culture Departments of the city of Suzano (state of São Paulo) established a partnership to implement the project Pavio Erótico, which is an Erotic Soirée that promotes films exhibitions, poems recitations, dialogs between the participants, literature interpretations, theater, dance, music, besides the distribution of contraceptives and folders. The material stimulates the discussion of human sexuality in light of safe sexual practices. It is a quarterly event and the target audience is composed of writers, poets, artists, teachers and the community in general. Some of the results obtained with the project are: incentive to reading and to erotic art; dissemination of the health services, enabling the expansion and the access to examinations, instructions and contraceptives; and the organization of the $1^{\text {st }}$ Erotic Literature Contest of Suzano. This innovative proposal promotes the development of culture in the city and expresses the health conception in which the focal point is not the disease.

Keyword: Intersectorial Action, Sexually Transmitted Diseases, prevention \& control, literature.

\section{Introdução}

A Secretaria de Cultura de Suzano tem desenvolvido vários projetos nas áreas de teatro, música, dança, cinema e literatura, tais como: Mostra de Referências Teatrais; Orquestra Jovem de Suzano; Grupo de Dança Afro; Roda de Todos os Santos e; especificamente em literatura, o projeto Trajetória Literária, com palestras de renomados escritores e poetas brasileiros; Pavio da Cultura (sarau literário) e o Pavio Erótico (sarau temático).

Em 2006, a Secretaria da Cultura - Coordenadoria Literária - e a Secretaria de Saúde - Coordenação do Programa Municipal de DST/Aids - de Suzano estabeleceram uma parceria para implantar o Projeto Pavio Erótico: sarau de literatura erótica, que traduz, em sua essência, recortes das expressões artísticas e culturais manifestadas na sexualidade humana, sendo um espaço rico para a atuação dos profissionais da saúde, que podem levar aos participantes informações sobre as DST/Aids.

\section{Objetivos}

Fomentar a produção e a valorização da arte erótica, enfocando as práticas sexuais seguras; fortalecer as ações intersetoriais no combate ao HIV/Aids e outras DST, por meio de ações de promoção e prevenção, previstas nas diretrizes do Sistema Local de Saúde em consonância com os princípios do Sistema Único de Saúde (SUS); ampliar o alcance das ações de promoção e prevenção ao HIV/Aids e outras DST.

\section{Metodologia}

No sarau temático, realizam-se: exibição de filmes, declamação de poesias, mesas de diálogo, interpretação de contos, apresentação teatral, apresentação de dança e música, além da disponibilização de preservativos e materiais informativos que fomentam as discussões do universo da sexualidade humana à luz das práticas sexuais seguras.

Cada participante realiza a sua apresentação em até 10 minutos. 0 conteúdo das apresentações pode ser de autoria própria ou escolhido no varal cultural, onde o participante pode optar por poemas, contos, poesias e crônicas. Os interessados em participar apresentando algum trabalho, chegam com 30 minutos de antece- 
dência para realizar as inscrições o que possibilita a organização das apresentações.

O evento é trimestral, com divulgação viabilizada por meio de folders, cartazes, agenda cultural, convites e no site da prefeitura .0 espaço utilizado para sua realização é o Anfiteatro do Centro Cultural "Francisco Carlos Moriconi”, na Rua Benjamin Constant, 682, Centro, Suzano, São Paulo. Tem como principal público-alvo escritores, poetas, artistas, professores e a comunidade em geral.

\section{Principais Resultados}

Com a realização de 11 edições do Pavio Erótico, foi possível obter grandes resultados, tais como: incentivo a leitura e a arte erótica; disponibilização de preservativos e materiais educativos durante os saraus; divulgação dos serviços de saúde, possibilitando a ampliação do acesso a exames, orientações, preservativos e encaminhamentos para tratamento se necessário. Além da realização do I Concurso de Literatura Erótica de Suzano (categorias: Conto e Poesia), que ocorreu entre os meses de setembro de 2007 e janeiro de 2008. Foram recebidas 120 inscrições de todo o Estado de São Paulo. Desse total, vinte textos foram selecionados e publicados no livro Amor Lúbrico - textos para serem lidos na cama, lançado no dia 28 de junho de 2008.

\section{Considerações Finais}

A proposta inovadora está sendo bem-sucedida e expressa uma concepção de saúde não focada na doença. O desenvolvimento da ação se dá em espaço saudável, que promove o desenvolvimento da cultura na cidade de Suzano. Dessa forma, o Programa Municipal DST/ Aids, em consonância com as diretrizes do Programa Nacional DST/Aids, busca colaborar com os municípios participantes da $8^{\mathrm{a}}$ Mostra Nacional de Experiências Bem-Sucedidas em Epidemiologia, Prevenção e Controle de Doenças, ao apresentar uma alternativa para enfrentar o desafio do combate as DST/HIV/Aids.

\section{Referências}

ANDRADE, C. D. $O$ amor natural. Rio de Janeiro: Editora Record, 1992.

ALBERONI, F. O Erotismo. São Paulo: Editora Rocco, 2006.

BEMFAM. Saber Ouvir, Saber Falar: um modelo de campanha informativa sobre a difusão da AIDS e a prevenção da doença. Rio de Janeiro, 1992. 